\title{
Oficina EtnoeducAtiva: uma proposta interdisciplinar de sensibilização socioambiental em área costeira
}

\author{
Ethnoeducational Workshop: an interdisciplinary proposal for socio-environmental \\ awareness in the coastal area
}

\begin{abstract}
Fernanda Vera Cruz Silva- Meneses', Marcelo Cesar de Lima Peres", Patricia Carla Barbosa Pimentel'I" , Eder Carvalho da Silvalv
\end{abstract}

\section{Resumo}

O termo Etno significa como grupos locais veem o mundo. O presente artigo tem por objetivo apresentar os resultados da proposição da oficina de educação ambiental intitulada EthoeducAtiva como estratégia de educação ambiental e reconhecimento da comunidade tradicional local. A etapa I do estudo e de caráter etnobiológico foi realizada em março a junho de 2017 com aplicação trinta e uma entrevistas semiestruturadas junto aos pescadores e marisqueiras de Arembepe. Para a análise dos dados utilizou-se a análise de conteúdo que permitiu a interpretação dos dados. Com o resultado parcial da pesquisa foi realizada a oficina experimental com estudantes do oitavo ano de uma escola de ensino fundamental II, inserida da área de estudo denominada EthoeducAtiva - etapa II. O desenvolvimento da oficina deu-se inicialmente através de uma proposta interdisciplinar entre as disciplinas de ciências naturais e língua portuguesa e foi elaborado um texto de cordel fruto da reflexão dos dados encontrados nas entrevistas. A oficina permitiu a associação do conhecimento tradicional com a formação educacional de estudantes em espaços formais de educação. Estratégias que oportunize a elaboração de cordéis ou qualquer outro produto devem ser estimuladas, sobretudo em países que possuem patrimônio natural e cultural tão diverso como o Brasil. Neste sentido, vislumbrase o desenvolvimento do saber cuidar do meio ambiente e valorização de comunidades tradicionais seja no âmbito local, com reflexões e ações para questões socioambientais em perspectiva global.

Palavras-chave: Educação ambiental; Conhecimento tradicional; Natureza e Sociedade; Arembepe; Cordel

\section{Abstract}

The term Ethno means how local groups see the world. The present article aims to present the outcome proposed by the environmental education workshop entitled EthoeducAtiva, as a strategy for environmental education and acknowledgement of the traditional local community. The first stage of the study, which had an ethnobiological character, was held from March to June 2017, by applying thirty-one semi-structured interviews with the fishermen and shellfisheries of Arembepe. For the data analysis it was used the content analysis, which allowed the data interpretation. With the partial result of the research, it was held an experimental workshop with students of the eighth grade of a high school, which was within the study area designated EthoeducAtiva - stage II. Initially, the workshop developed through an interdisciplinary proposal between the school subjects of natural sciences and Portuguese language. As a result of the reflection upon the data found in the interviews, a Cordel text was produced. The EthoeducAtiva workshop allowed the association of traditional knowledge with the educational training of students in formal educational spaces. Strategies that encourage the elaboration of Cordeis or any other product should be stimulated, particularly in countries which have such a diverse natural and cultural heritage as Brazil. In that regard, it is aimed the development of the know how to take care of the environment and the valorization of traditional communities at the local level, with reflections and actions for social and environmental issues in a global perspective.

Keywords: Environmental education; Traditional knowledge; Nature and Society; Arembepe; Cordel 


\section{Introdução}

O termo Etno usado antes de palavras como, ictiológico, biológico, ecológico, conservação significa como grupos locais veem o mundo. O prefixo é utilizado antes dos nomes de disciplinas acadêmicas e está relacionado à pesquisa com grupos locais e tradicionais e o conhecimento científico (MARTIN, 2004; ALBURQUERQUE; ALVES, 2014).

Essa interação estabelecida pelo homem com a natureza é estudada pela etnociências. A Etnociência proporciona a conexão de conhecimentos sobre a natureza, que são de propriedade de pessoas, grupos e comunidades, que acumulam saberes sobre o meio natural, estabelecida por uma relação longa e, muitas vezes, não é registrada por escrito, e /ou mesmo, mais ricos e detalhados do que o conhecimento da ciência moderna (PEREIRA; DIEGUES, 2010). Os autores ainda consideram que:

A etnociência exige a articulação entre o natural e o social, utilizando como metodologia a investigação das nomenclaturas designadas pelas populações tradicionais para os elementos e fenômenos naturais, assim como os valores culturais que transportam (PEREIRA; DIEGUES, 2010, p.43).

Portanto, um dos objetivos da etnobiologia é procurar compreender/entender como são percebidos os seres vivos, como eles são classificados pelas culturas humanas e como são conhecidos (MOURÃO; MONTENEGRO, 2010). Albuquerque e Alves (2014, p. 20) ressaltam que "O conhecimento tradicional não se restringe aos organismos, mas inclui percepções e explicações sobre a paisagem e a geomorfologia e sobre a relação entre os diferentes seres vivos com o ambiente físico".

Para tanto, o meio ambiente é uma unidade que precisa ser compreendida na totalidade. Através de ações e projetos interdisciplinares e de uma visão holística da natureza será possível assegurar que as futuras gerações tenham acesso ao meio ambiente em equilíbrio (ANDREOLI; ANACLETO, 2006).

Assim, focamos atenção para as contribuições do conhecimento tradicional, especificamente, o de pescadores artesanais.

Meireles et al. (2017) notam que os pescadores, por utilizarem o ecossistema aquático, possuem compreensão sobre fauna aquática e são conhecedores de saberes ecológicos resultantes da interação como o meio pesqueiro, onde a arte da pesca possui contornos na relação de subsistência e no enfoque econômico. Onde os detalhes percebidos e aprendidos através da observação empírica dos elementos do meio ambiente, resultante da relação estabelecida na dinâmica como o meio natural, constituem um sistema detalhado na mente do povo tradicional (TOLEDO; BARRERA-BASSOLS, 2009). O pescador e a marisqueira, capturam presas - os peixes e mariscos uma vez que o desenvolvimento da atividade pesqueira artesanal depende diretamente dos elementos naturais do ecossistema aquático - rios ou mares (CLAUZET; RAMIRES; BEGOSSI, 2007).

Hanazaki (2016, s.p.) considera que o conhecimento local e as experiências com os recursos naturais são relevantes:

Primeiro, um arcabouço teórico e metodológico para compreender sistemas de percepção, cognição e classificação do ambiente natural por sociedades locais ou tradicionais. Segundo, o estabelecimento de uma ligação direta entre o conhecimento construído localmente e o conhecimento cientifico. Terceiro, a possibilidade de resgatar e valorizar um conhecimento que tende a desaparecer rapidamente.

Neste contexto, o arcabouço teórico, para iniciar esse diálogo com estudantes de uma escola de ensino fundamental II, parte do campo teórico da etnociência, tratando-se aqui, especificamente, do conhecimento etnobiológico/etnoecológico, que possui potencial de interação entre os conhecimentos globais, locais e de conexão entre a cultura de tradições e os conhecimentos acadêmicos, sem dispensar a experiência humana e o ambiente. Ocupa, portanto, posição de destaque na interação dos conhecimentos científicos e não científicos, na compreensão e no meio para conservação do ambiente local (ALBURQUERQUE; ALVES, 2014).

Ao associar o conhecimento local de uma comunidade de pescadores e o conhecimento científico, compõe-se uma teia educativa enaltecendo a ideia que o saber tradicional é relevante na construção do conhecimento, da percepção e reflexão sobre a dependência que temos da natureza. Nesse sentido, a educação ambiental é um caminho possível para se pensar a relação do homem com a natureza, por meio da transferência de conhecimentos ecológicos e socioculturais locais, fortalecendo os diferentes conhecimentos para disseminação de estratégias de educação ambiental em espaços formais (OLIVEIRA JUNIOR; SATO, 2006).

Destaca-se, a partir do pensamento de Boff (2014), que o cuidado com a natureza será efetivo, se passarmos todos nós pelo processo de educação, através das trocas feitas e pelo acesso à informação estabelecida pela junção de saberes. O saber ancestral tradicional, acumulado nas tradições dos velhos, dos povos indígenas, dos quilombolas, dos imigrantes, dos pescadores e marisqueiras, saberes que são profundos e detalhados, estabelecidos pela ligação com a natureza por meio de práticas culturais, associado ao diálogo com o conhecimento acadêmico, compõem um caminho para o efetivo cuidado ecológico, compondo, assim, um meio de reflexão em EA, para o desenvolvimento de condutas ambientais éticas com vistas à valorização da natureza. Tem-se na rotina local a prática da pesca e mariscagem, vínculo ancestral, conhecimento sobre a natureza, transmissão do conhecimento tradicional dos velhos aos mais novos, relação cultural e simbólica, e da necessidade de conservação de um espaço de vida no qual comunidade costeiras fazem partes (RIBEIRO, 2018).

Tem-se, portanto, por objetivo apresentar os resultados da proposição da oficina de educação ambiental intitulada EthoeducAtiva como estratégia de educação ambiental e reconhecimento da comunidade tradicional local. 


\section{Procedimentos metodológicos}

\section{1. Área de Estudo}

Arembepe está localizada as margens da BA-099, conhecida por estrada do Coco, com latitude $12^{\circ} 77^{\prime} 18^{\prime \prime}$ $S$ e longitude $38^{\circ} 17^{\prime} 62^{\prime \prime}$ O. É um lugar singular, de rica natureza e cultura, situado entre lagoas e o oceano. A localidade possui a tradição pesqueira e dispõe de atributos naturais e históricos. A etimologia da palavra vem do tupi guarani, portanto, Arembepe significa "aquilo que nos envolve". A localidade está associada à aldeia Hippie, que, nos anos 70, recebeu o movimento Hippie de paz e amor. Famosa, pois passaram pela Aldeia personalidades como Janis Joplin, Mick Jagger e Roman Polanski. (KOTTAK, 1999; PROJETO TAMAR, 2018).

\subsection{A pesquisa}

Trata-se de um estudo de caso, de natureza etnobiológica e de abordagem qualitativa. Os sujeitos envolvidos na pesquisa durante a etapa I foram os pescadores artesanais - pescadores e marisqueiras - vinculados à colônia de pesca Z-14. O número de pescadores artesanais de Arembepe é de 72 indivíduos. O critério de inclusão e exclusão dos participantes obedeceu ao seguinte pressuposto: aqueles que residiam e praticavam a pesca partindo de Arembepe e possuíam idade de $\geq 40$ anos. O fator experiência aqui é justificado por Begossi (2004, p.244) como:

[...] a idade é uma variável que influencia no grau de conhecimento sobre os pesqueiros, o que confirma a expectativa sobre a importância de incluir na amostra, pescadores experientes (considerando que há maior experiência entre os mais idosos, que pescam há mais tempo que os mais novos).

No total foram entrevistados 31 , ou seja, $43 \%$ dos pescadores artesanais (pescadores e marisqueiras) vinculados à colônia de pesca Z-14 e residentes na localidade de estudo. A pesquisa se deu por meio de entrevista semiestruturada, dividida em dados socioeconômicos, método, tradição e cultura, conhecimento etnobiológicos e percepção ambiental.

Os dados coletados sobre método, tradição e cultura foram categorizados e tabulados por unidades temáticas utilizando estatística descritiva em planilha Microsoft Excel. Para a análise dos dados qualitativos, utilizou-se o método da análise de conteúdo com abordagem para a análise temática de conteúdo (BARDIN, 1977). Emergiram subcategorias temáticas (apetrechos, organização social, método de localização da área de pesca, como se dá a transmisaaõ do conhecimento, cultura etc.) a partir da análise interpretativa do contexto das respostas, da intensa leitura do material analisado e da fundamentação proveniente do campo empírico (CAMPOS, 2004).

Para o desenvolvimento da etapa II foi elaborado um roteiro para a execução da oficina (figura 1) de caráter experimental e proposição interdisciplinar entre as disciplinas de língua portuguesa, ciências naturais e artes.
Com os resultados parciais do item método, tradição e cultura da pesquisa de campo realizada junto aos pescadores artesanais foi elaborada aula expositiva e dialogada de educação ambiental.

Figura 1 - Roteiro previamente elaborado para a execução da oficina experimental entre estudantes do oitavo ano do ensino fundamental II, em escola inserida na área de estudo (Set, 2017)

A oficina tem como proposta a elaboração de cordéis, junto aos estudantes do CMPLCP, para que possam refletir sobre a interaçăo homem e natureza local, a partir da socialização do resultado da pesquisa realizada na comuridade de Arembepe, que possibilitou acessar o conhecimento tradicional. Constitui-se uma atividade interdisciplinar, a princípio, entre a área de linguagem (língua portuguesa e artes) e ciências da natureza podendo envolver, ainda, outras áreas do conhecimento.

Material

- Aula com socialização do resultado e discussão oriunda da pesquisa

- Papel ofício cujo verso apresente-se sem uso

- Tinta guache.

- Pincel.

- Isopor para reutilização (tipo de pratos para embalagem de queijo e presunto). Etapal

- Aula expositiva e dialog ada sobre literatura de cordel

- Aula dialogada sobre os resultados da pesquisa com participaçăo de pescadores e marisqueiras

- Divisão da turma em pequenos grupos

- Sensibilização para a elaboração de cordel.

- Revisão dos cordéis através da troca entre os grupos.

Etapall

- Arte dos cordéis com uma técrica simples de xilogravura em isopor (com material reutilizável) (Fonte: https://Www. youtube.com/watch?v=gWQc0Fbks $\$ \mathrm{k} /$ ). acesso em 2017 Conclusäo da oficina

Espera-se que os cordéis produzidos na oficina possam auxiliar práticas pedagógicas æensibilizadoras em EA, em diferentes áreas do conhecimento, através da interdisciplinaridade.

Fonte: Elaboração dos autores

A oficina intitulada EtnoeducAtiva de caráter experimental ocorreu em três encontros de cinquenta minutos com a participação de seis estudantes do oitavo ano do ensino fundamental II, no ano de 2017, selecionados a partir dos conceitos avaliativos da unidade escolar.. Nessa fase da educação básica e em função da idade os estudantes apresentam relação mais próxima com o ambiente local por praticarem diversas atividades como surf, capoeira e outras ligadas ao Projeto Tamar. A escolha do colégio municipal Profa. Lídia Coelho Pinto (CMPLCP) justifica-se pelo fato de ser a única escola da localidade em estudo que oferta o ensino fundamental II. Para além disso, como docente da disciplina de Ciências, práticas interdisciplinares vêm sendo desenvolvidas na unidade escolar juntamente com as disciplinas de Língua Portuguesa e Matemática.

A pesquisa foi submetida ao Comitê de Ética em Pesquisa da Universidade Católica do Salvador, em setembro de 2016, obtendo aprovação através do parecer número 1.819.813, de 14 de novembro de 2016 . 


\section{Resultado e discussões}

\subsection{A oficina}

Como pressuposto para participação na oficina EthoeducAtiva os estudantes deveriam possuir habilidades e competências relativas a literatura de cordel. Os conhecimentos prévios sobre poema, versos, estrofes, narrativa, métrica, rima e ritmos foram trabalhados nas aulas de língua portuguesa durante a unidade II. No decorrer das aulas de ciências naturais foi apresentado como tema o Método, a Tradição e a Cultura dos pescadores e marisqueiras da Vila de Arembepe, ou seja, a história viva a ser contada na forma de cordel compondo a estratégia de educação ambiental.

Para Marcondes (2008, p.68),

A oficina, no sentido que se quer atribuir, pode representar um local de trabalho em que se buscam soluções para um problema a partir dos conhecimentos práticos e teóricos. Tem-se um problema a resolver que requer competências, o emprego de ferramentas adequadas e, às vezes, de improvisações, pensadas na base de um conhecimento. Requer trabalho em equipe, ação e reflexão. As oficinas são temáticas, na perspectiva de tratar de uma dada situação problema que, mesmo tendo um dado foco, é multifacetada e sujeita a diferentes interpretações.

Dentre os resultados relacionados ao Método, Tradição e Cultura, apresentados nas aulas ciências, destacaram-se o método de pesca local é o artesanal e ocorrem em lagoas, rios e mar; as embarcações utilizadas para a pesca no ambiente marinho costeiro são de médio porte, de madeira e equipadas com motor; como os apetrechos utilizados na atividade pesqueira tem-se o jereré, o cofo, a rede, os tresmalhos, a boia, o aço, o anzol etc. Foi informado aos estudantes que os pescadores estão vinculados e representados pela colônia de pescadores Z-14 e que dentro das embarcações são os mestres que organizam a logística para a pesca e orienta sobre o local dos pesqueiros ${ }^{\mathrm{I}}$.

As atividades relacionadas a pesca desempenhadas por marisqueiras se destacam pela cooperação entre elas, e portanto, sem hierarquia definida, como ocorre entre pescadores. Como já mencionado, a identificação do pesqueiro e zonas de pesca ocorrem por meio de um "sistema próprio de cartografia” (SILVA, 2007), no qual são utilizados como referência morros, depressões/declives no relevo da costa, ou torres de igrejas e antenas de celulares. Como apoio aos métodos tradicionais de identificação do pesqueiro, novas tecnologias tem sido utilizadas pelos pescadores como sistemas de posicionamento global (GPS).

Um dos aspectos mencionados durante as oficinas foi que $42,5 \%$ dos pescadores e marisqueiras aprenderam a arte da pesca por influência do pai ou mãe, $25,9 \%$ com pessoas mais experientes da comunidade, $16,1 \%$ foram

Pesqueiros, segundo a conhecimento tradicional dos pescadores artesanais, são áreas de pesca onde são encontrados os cardumes. motivados pela curiosidade e dom, $6,4 \%$ com os avós e $6,4 \%$ com os tios. Outro aspecto que mereceu abordagem durante as oficinas foi a participação de pescadores e marisqueiras no movimento cultural denominado de Chegança ${ }^{\mathrm{II}}$.

Assim, a valorização do conhecimento tradicional de pescadores e marisqueiras é uma preciosa fonte de informação e conhecimento para a aplicação de projetos voltados para EA, que, além da manutenção da cultura local, compõe uma importante estratégia de gestão ambiental, uma vez que é mais fácil de ser posto em prática e incorporado pela comunidade local, quando é percebido pelos demais, a importância socioambiental da atividade (EVANGELISTA-BARRETO et. al., 2014).

Medina (1998) considera que através da educação ambiental constroem-se relações culturais, sociais, que se constituem, portanto, em uma estratégia de incorporação e compreensão de diferenças dando início ao pensar com respeito à cerca das minorias, a exemplo, dos povos e comunidades tradicionais, bem como refletir sobre os limites dos ecossistemas e sobre nossa sobrevivência frente ao desequilíbrio ambiental.

Um dado relevante é que $90,3 \%$ dos entrevistados possuem filhos, dos quais, $87,1 \%$, estudaram ou estudam em escolas da comunidade. A ideia de se realizar a oficina EtnoeducAtiva e a literatura de Cordel surge com o propósito de perpetuar o conhecimento tradicional, bem como promover a reflexão sobre a questão ambiental e a dependência homem X natureza.

É importante mencionar que muitos dos estudantes da mencionada unidade escolar são filhos e netos de pescadores e marisqueiras dessa comunidade e que tem perdido o contato com essa realidade da Vila de Pescadores devido aos interesses e possibilidades que o mundo afora supostamente os tem proporcionado.

Nesse sentido, considera-se a proposta significativa visto que, a elaboração, a construção, o pensamento para o desenvolvimento da linguagem escrita, como uma das propostas dessa oficina. Expressões, ideias e reflexões dos estudantes, frente ao proposto derivam de um trabalho de análise e discussão. A elaboração do material escrito é fonte de informação e conhecimento para novas abordagens reflexivas em outras ações de EA, têm-se, por conseguinte, material para divulgação em práticas pedagógicas interdisciplinares abrangendo outras disciplinas, a exemplo história, geografia e artes.

Tamaio e Layrargues (2014) consideram que as riquezas ambientais podem contribuir muito para o autoconhecimento do indivíduo, proporcionando excelentes formas de aprendizagem e contribuindo muito para o respeito ao lugar, o respeito do ser humano pela natureza, chegando à elevada sensibilização social pela causa ambiental.

\subsection{0 cordel}

Então, ao propor a linguagem do cordel, como canal de comunicação dos resultados e discussões da pesquisa,

\footnotetext{
Movimento cultural que narra através do canto e da dança uma luta em alto mar. Suas vestes remetem a uniformes que de marinheiros (REVISTA DO FESTIVAL, 2016).
} 
entende-se que esse texto é um meio de comunicação que permite compartilhar, diretamente com a sociedade, fatos, situações, experiências. Trata-se, desse modo, de um meio popular para orientar e informar muitas pessoas (ACIOLI, 2010).

O cordel apresenta conectividade representativa com os conhecimentos oriundos da etno, ou seja, dos povos tradicionais, uma vez que sua origem se dá no período colonial com a trova portuguesa, se unindo à poesia do caboclo, surgindo, então, um estilo literário sertanejo, criativo e alegre (ACIOLI, 2010), configurando uma literatura resultante da mistura de conhecimento, dos povos portugueses, indígenas e negros.

Para tanto, uma vez resgatada e colocada em discussão, à valorização desse saber possibilitará uma nova forma de pensamento integrador em pesquisas, no ensino, possibilitando que a diversidade biológica seja conservada (MOURÃO; MONTENEGRO, 2010). Os cordéis produzidos na oficina EthoeducAtiva são instrumentos que auxiliarão as práticas pedagógicas sensibilizadoras em EA, em diferentes áreas do conhecimento, através da interdisciplinaridade (Figura 2).

Figura 2 - Texto do cordel elaborado por estudantes do oitavo ano do ensino fundamental Il durante a execução de oficina experimental EthoeducAtiva (set, 2017).

De séculoé tradição

Passa de geração em geração

Dos avós para os netos

E todos os seusirmãos

Fazem desse conhecimento

O portal da transmissão

O peixe tão esperado na mesa do jantar

No oceano os pescadores o dinheiro vaiganhar

Para dar a sua família o prazer de alimentar

E quando dizem que ele tem uma vida sofredora

Ele diz que tem amor a sua vida lutadora

\section{Começarama remar}

Falaram que ele sofre em alto mar

Pois antes de sair sua família teve que deixar

E os filhos dizem: - Pai não nos deixe.

Mas ele os abraça, dizendo com o peixe vou voltar

Dito e feito ele volta, com o alimento,

Pois foi trazido em alto mar

Pelo frio do vento

O dinheiro chegou emótima situação

Por isso fizeram grande comemoração

Depois de uns dias, eles se jogam no mar

Direto pros corais, para os peixes encontrar

Infelizmentenada pescaram

E para casa voltam

A família como fome começou a ficar

E o pescador outro emprego foi buscar

Mas da pesca sentiafalta

Por adorar jogar rede em alto mar

Em cima do barco começou a remar

$\mathrm{Na}$ felicidade do peixe ao olhar
Os pescadores e marisqueiras de Arembepetemgrande

conhecimento

Domínio de como pescar

É seu grande talento

Sabem onde pescar

Usando a melhor técnica paracapturar

No universo da marisqueiras é mais fácil de pescar

Os peixes vão pra rede

Sem ela ter que procurar

Difícil mesmo é pescar o camarão

Por conta da escassez

E o tucunaré que pula da redena sua vez

Em vez de lamentar

A vida difícil do mar

Elas precisam pescar

Os diversos tipos de mariscos

Para seus filhos sustentar

A chegança feminina masculina

Com canto e dança na terra

Conta mesmoé a historia em alto mar

Dos portugueses que vieram a colonizar

Vestem-sede marinheiros

Neste ambiente costeiro

Entram em seus barcos pesqueiros

Pescam quaseo dia inteiro

Para poder render o dinheiro

(Autoria: estudantes do 8 ano da CMPLCP - 2018) 


\section{Conclusões}

Oficinas EtnoeducaAtivas, seja para elaboração de cordéis ou qualquer outro produto que oportunize a associação do conhecimento tradicional com a formação educacional de estudantes em espaços formais de educação, são estratégias que devem ser estimuladas sobretudo em países que possuem um patrimônio natural e cultural tão diverso como o Brasil.

Os currículos e o material didático dissociados da realidade local evidenciam a ausência de políticas públicas e educacionais efetivas e que permitam a promoção e valorização dos atributos locais e do pensamento crítico e, consequentemente, do desenvolvimento do saber cuidar do meio ambiente, da cultura, e dos povos tradicional, seja no âmbito local, com reflexos para questões ambientais em perspectiva global.

\section{Agradecimentos}

Agradecimentos aos pescadores e marisqueiras de Arembepe, Bahia.

\section{Referências}

ACIOLI A.S. Literatura popular como ferramenta para a educação ambiental. Revista brasileira de educação ambiental.2010:v.5:76-83.

ALBUQUERQUE U.P, ALVES G.C.A. O que é etnobiologia? In: ALBUQUERQUE, U.P. Introdução à Etnobiologia. Recife: NUPPEA;2014.17-22.

ANDREOLI V.M, ANACLETO A. Compartilhando saberes: os conhecimentos tradicionais e a educação ambiental. In: Encontro Paranaense de Educação Ambiental - EPEA, IX.2006:s.p.

BARDIN L. Análise de Conteúdo. Presses Universitaires de France:1977.

BEGOSSI A. Áreas, pontos de pesca, pesqueiros e territórios na pesca artesanal. In: BEGOSSI, A. (Org). Ecologia de pescadores da Mata Atlântica e da Amazônia. São Paulo: HUCITEC, NEPAM/UNICAMP/ NUPAUB/USP - Fabesp;2004. p. 223-253.

BOFF L. Saber cuidar. 20.ed. Petrópolis: Vozes; 2014.

CAMPOS C.J.G. Método de Análise de conteúdo: ferramenta para a análise de dados qualitativos no campo da saúde. Revista Brasileira Enfermagem. Brasília; 2004.p. 611-614.

CLAUZET M, RAMIRES, M, BEGOSSI, A. Etnoictiologia dos pescadores artesanais da praia de Guaibim, Valença, BA, Brasil. Neotropical Biology and Conservation.2007:136-154.
EVANGELISTA-BARRETO N.S. et al. Indicadores socioeconômicos e percepção ambiental de pescadores em São Francisco do Conde, Bahia. Bol. Inst. Pesca. 2014:459-470.

HANAZAKI N. Etnoecologia, etnobiologia e as interfaces entre o conhecimento científico e o conhecimento local. In: Anais da Reunião Anual da SBPC [Internet]; 2006 julho; Florianopolis, Brasil [cited 2019 fev 15]: http://www. sbpcnet.org.br/livro/58ra/atividades/TEXTOS/texto_290. html.

KOTTAK C.P. Assault on Paradise: Social Change in a Brazilian Village. USA. McGraw-Hill Companies, Inc. 1999.

MARCONDES M. E. R. Proposições metodológicas para o ensino de química: oficinas temáticas para a aprendizagem da ciência e o desenvolvimento da cidadania. EM EXTENSÃO.2008; V. 7:67-77.

MARTIN G. J. Etnobotany, a methods manual. Earthscan London; 2004.

MEDINA N.M. Educar - uma perspectiva humanística. Congresso Internacional de Educação do Colégio Coração de Jesus; 1998 Junho; Florianópolis;2000

MEIRELES M.P.A, MEIRELES, V.J.S, VIEIRA, L.S,. BARROS R.F.M. Características da pesca artesanal realizada na comunidade Passarinho/Ilha das Canárias/ MA. Gaia Scientia.2017;12-26.

MOURÃO J. S, MONTENEGRO, S. C. S. Pescadores e Peixes: o conhecimento local e o uso da taxonomia folk baseado no modelo berlineano. vol. 2, Recife: NUPPEA; 2010.

OLIVEIRA JUNIOR, S, SATO, M. Educação Ambiental e Etnoconhecimento: parceiras para a conservação da diversidade de aves pantaneiras. Ambiente e Educação.2006. V. 11: 125-137.

PEREIRA, B. E, DIEGUES, A. C. Conhecimento de populações tradicionais como possibilidade de conservação da natureza: uma reflexão sobre a perspectiva da etnoconservação. Desenvolvimento e Meio ambiente.2010: 37-50.

PROJETO TAMAR [Internet]. Arembepe-Ba. Brasil.[cited 2019 feb 15] http://www.tamar.org.br/centros_visitantes. php? cod $=2$.

RIBEIRO A.S, ROSA R.R.G, BUSSOLETTI D.M, HAERTER L. A água como destino: na colônia de pescadores Z-3, territórios e territorialidades entre mar e terra. Revista memória em rede.2018;v.10:2177-4129. 
REVISTA DO FESTIVAL, SECULT. 2016:p36-37.

SILVA C.N, A percepção territorial-ambiental em zonas de pesca. Boletim do Museu Paraense Emilio Goeldi. Ciências Humanas.2007:V.2:25-32.

TAMAIO I, LAYRARGUES P. P. Quando o parque (ainda) não é nosso: educação ambiental, pertencimento e participação social no Parque Sucupira, Planaltina (DF). Espaço \& Geografia.2014:V.17: 145-182.

TOLEDO V. M, BARREREA-BASSOLS N. A etnoecologia: uma ciência pós-normal que estuda as sabedorias tradicionais. Desenvolvimento e Meio Ambiente.2009: 31-45. 